\title{
Occurrence of MCPD and glycidyl fatty acid esters in standard and specialized infant formula in Denmark
}

\author{
Nguyen, Khanh Hoang; Fromberg, Arvid
}

Published in:

Food Additives \& Contaminants: Part A - Chemistry, Analysis, Control, Exposure \& Risk Assessment

Link to article, DOI:

$10.1080 / 19440049.2020 .1817572$

Publication date:

2020

Document Version

Peer reviewed version

Link back to DTU Orbit

Citation (APA):

Nguyen, K. H., \& Fromberg, A. (2020). Occurrence of MCPD and glycidyl fatty acid esters in standard and specialized infant formula in Denmark. Food Additives \& Contaminants: Part A - Chemistry, Analysis, Control, Exposure \& Risk Assessment, 37(11), 1847-1853. https://doi.org/10.1080/19440049.2020.1817572

\section{General rights}

Copyright and moral rights for the publications made accessible in the public portal are retained by the authors and/or other copyright owners and it is a condition of accessing publications that users recognise and abide by the legal requirements associated with these rights.

- Users may download and print one copy of any publication from the public portal for the purpose of private study or research.

- You may not further distribute the material or use it for any profit-making activity or commercial gain

- You may freely distribute the URL identifying the publication in the public portal 
1 Occurrence of MCPD and glycidyl fatty acid esters in standard and specialized infant 2 formula in Denmark

3

4 Khanh Hoang NGUYEN*, Arvid FROMBERG

5 National Food Institute, Technical University of Denmark, 2800 Kgs. Lyngby, Denmark

$6 \quad *$ Corresponding author: khng@food.dtu.dk 


\section{Introduction}

Monochloropropanediol fatty acid esters (MCPDEs) and glycidyl fatty acid esters (GEs) are food processing contaminants that are formed during the thermal processing of fat via different mechanisms (Cao et al., 2019; Cheng, Liu, \& Liu, 2016; Zhang et al., 2015). MCPDEs consist of two isomers depending on the position of chlorine on the propane backbone namely 2-MCPDEs and 3-MCPDEs while GEs do not have any isomers. These chemicals are well-known to present in refined vegetable oils such as palm oil or pomace olive oil due to the high temperature utilized in oil deodorization processes (EFSA CONTAM Panel, 2016; Kuhlmann, 2011). Since vegetable oils are often used in infant formula to mimic the fat composition of breast milk, infants could be exposed to MCPDEs and GEs through formula consumption. This is of high concern because 3-MCPDEs and GEs are hydrolyzed in the human gastrointestinal tract into their corresponding free form 3-MCPD and glycidol which are carcinogens according to the International Agency for Research on Cancer (IARC) (EFSA CONTAM Panel, 2016; IARC, 2000, 2013).

To date, there are still very limited studies on MCPDEs and GEs in infant formula and complex foods. However, several studies have reported the occurrence of MCPDEs and GEs in infant formula worldwide (Arisseto, Silva, Scaranelo, \& Vicente, 2017; Becalski, Zhao, Feng, \& Lau, 2015; Beekman, Grassi, \& MacMahon, 2020; BLE, 2016; Nguyen \& Fromberg, 2020; Wöhrlin, Fry, Lahrssen-Wiederholt, \& Preiß-Weigert, 2015). For instance, Arisseto et al., 2017 measured concentrations of 3-MCPDEs and GEs in the range of not detected (ND) to $600 \mu \mathrm{g} / \mathrm{kg}$ and ND to $750 \mu \mathrm{g} / \mathrm{kg}$, respectively, in powder infant formula from the Brazilian market. Our previous published study has also provided a preliminary assessment of MCPDEs and GEs in Danish liquid and powder formula (n=13) sampled in early 2019.

In this study, we aim to investigate more in-depth the degree of MCPDEs and GEs contamination in a wider range of infant formula in Denmark which covered both standard and 
specialized products. Standard formula products are often readily available at supermarkets which are intended for healthy infants without any dietary or medical issues. Specialized formula is usually available at pharmacies and designed for infants with special nutritional requirements due to specific medical conditions e.g. premature newborns or infants with cow milk protein allergy (Dipasquale, Serra, Corsello, \& Romano, 2020).

\section{Materials and methods}

\subsection{Chemicals and standards}

Ethyl acetate, methanol, and toluene (at least 99.8\%) were purchased from Rathburn Chemicals Ltd. (Walkerburn, United Kingdom). Ammonium sulfate (99.5\%), sodium sulfate anhydrous (99\%), sulfuric acid (95-97\%), diethyl ether (97\%), isooctane (99.8\%), n-hexane (99.3\%), and n-heptane (99.3\%) were acquired from Merck (Darmstadt, Germany). Sodium hydrogen carbonate (99.7\%), sodium bromide (99.5\%), phenylboronic acid (PBA, 97\%), and tetrahydrofuran (THF, 99.9\%) were purchased from Sigma-Aldrich Chemical (Missouri, U.S.A). Water was obtained from a Millipore Milli-Q system (Merch, Darmstadt, Germany).

Native standards (rac 1,2-bis-palmitoyl-3-chloropropanediol, 1,3-bis-palmitoyl-2chloropropanediol (98\%), and glycidyl palmitate) and internal standards ( rac 1,2-bispalmitoyl-3-chloropropanediol-d5, 1,3-bis-palmitoyl-2-chloropropanediol-d5, and glycidyl palmitate d5) were purchased from Toronto Research Chemicals (Ontario, Canada) at the highest available purity. The stock and working solutions were prepared in toluene and stored at $-18^{\circ} \mathrm{C}$.

\subsection{Sample collection}

Forty-two infant formula products from different manufacturers were purchased at physical and online supermarkets and pharmacies in Denmark during the spring of 2020. The samples covered almost all available infant formula products on the Danish market and 
comprised of standard and specialized powder products and standard liquid formula. The sample details can be seen in Table 1 . Upon receipt, the samples were stored at ambient conditions until analysis.

\subsection{Analytical method}

60 previously published study (Nguyen \& Fromberg, 2020). The method was in-house validated and accredited according to ISO 17025:2017 by the Danish Accreditation Fund (DANAK).

\subsubsection{Sample preparation}

An amount of sample containing approximately $100 \mathrm{mg}$ of fat was weighed into a conical centrifuge tube and spiked with $250 \mathrm{ng}$ of internal standards. Twelve $\mathrm{mL}$ each of MilliQ water and ethyl acetate were added and the sample was vortexed for $10 \mathrm{~s}$ then ultrasonicated for $15 \mathrm{~min}$ at $50{ }^{\circ} \mathrm{C}$. The contaminants were extracted by high speed liquid-liquid extraction using a Geno Grinder 2100 (SPEX SamplePrep, U.S.A) at $1500 \mathrm{rpm}$ for $5 \mathrm{~min}$. Sodium sulfate anhydrous (10 g) was added to assist phase separation and the sample was shaken again at 1500 rpm for $3 \mathrm{~min}$. After centrifugation at $4800 \mathrm{rpm}$, the upper layer was collected and the extraction process was carried out once more with $12 \mathrm{~mL}$ ethyl acetate. The combined upper layer containing the analytes of interest was evaporated to dryness by nitrogen stream at $40{ }^{\circ} \mathrm{C}$ then re-dissolved in $1 \mathrm{~mL}$ of $\mathrm{n}$-hexane:ethylacetate $(85: 15, \mathrm{v} / \mathrm{v})$ mixture. The sample was loaded on an aminopropyl SPE cartridge (6 cc, $500 \mathrm{mg}$, Supelclean ${ }^{\mathrm{TM}} \mathrm{LC}^{-\mathrm{NH}_{2}}$, Sigma-Aldrich, U.S.A) and eluted with $10 \mathrm{~mL}$ of n-hexane:ethylacetate $(85: 15, \mathrm{v} / \mathrm{v})$. The cleaned-up sample was evaporated to dryness under a nitrogen stream at $40{ }^{\circ} \mathrm{C}$ then redissolved in $2 \mathrm{~mL}$ of THF for bromination of GEs.

The bromination of GEs into 3-monobromopropanediol esters (3-MBPDEs) took place by incubating the mixture of the cleaned-up sample in THF and $30 \mu \mathrm{L}$ of an acid aqueous solution of sodium bromide (sodium bromide $3 \mathrm{mg} / \mathrm{mL}$, sulfuric acid $5 \% \mathrm{v} / \mathrm{v}$ ) for $15 \mathrm{~min}$ at 50 
$81{ }^{\circ} \mathrm{C}$. The reaction was stopped by $3 \mathrm{~mL}$ of sodium bicarbonate $0.6 \%$ solution and the contaminants were extracted using $2 \mathrm{~mL}$ of $\mathrm{n}$-heptane followed by evaporation to dryness under a nitrogen stream at $40^{\circ} \mathrm{C}$. A $1 \mathrm{~mL}$ portion of THF was added to redissolve the sample and the sample was subjected to acid methanolysis by adding $1.8 \mathrm{~mL}$ of sulfuric acid in methanol solution $(1.8 \% \mathrm{v} / \mathrm{v})$ then incubated for $16 \mathrm{~h}$ at $40{ }^{\circ} \mathrm{C}$. After the incubation period, $0.5 \mathrm{~mL}$ of saturated sodium bicarbonate solution was added and the remaining organic solvents were evaporated under a nitrogen stream at $40{ }^{\circ} \mathrm{C}$. Afterward, fatty acid methyl esters were salted out from the sample by $1.3 \mathrm{~mL}$ of ammonium sulfate solution $(40 \% \mathrm{w} / \mathrm{v})$ and cleaned-up with $2 \mathrm{~mL}$ of n-heptane twice. Free forms of 3-MCPDEs, 2-MCPDEs, and 3-MBPDEs were extracted out of the aqueous phase twice by $2 \mathrm{~mL}$ of ethyl acetate. The combined extracted was derivatized by added $150 \mu \mathrm{L}$ of PBA in diethyl ether solution $(4 \% \mathrm{w} / \mathrm{v})$ then ultrasonicated for $5 \mathrm{~min}$ at room temperature. After the derivatization process, the sample was gently evaporated to dryness under a nitrogen stream at $40{ }^{\circ} \mathrm{C}$ and reconstituted in $300 \mu \mathrm{L}$ of isooctane. The isooctane aliquot was stored at $-18{ }^{\circ} \mathrm{C}$ for $2 \mathrm{~h}$ and precipitated derivatization reagent was filtered out by a Mini Uni-Prep $(0.45 \mu \mathrm{m}$, PFTE media). The filtered supernatant was transferred to a GC glass vial and analyzed by GC-MS/MS.

\subsubsection{Instrument analysis}

The instrument analysis was performed on a GC-MS/MS system (Thermo Fisher Scientific, U.S.A) comprised of a Trace 1300 gas chromatography, a TSQ 8000 EVO triple quadrupole mass spectrometer, and a Triplus RSH autosampler. The gas chromatography was equipped with a Supelco Equity-1 capillary column $(30 \mathrm{~m}$ x $0.25 \mathrm{~mm}$ i.d. x $1.00 \mu \mathrm{m}$ film thickness, Sigma-Aldrich, Missouri, U.S.A). Samples were injected in PTV splitless mode with the following parameters: $1.5 \mathrm{~mL} / \mathrm{min}$ constant helium flow rate, $1 \mu \mathrm{L}$ injection, $0.5 \mathrm{~min}$ splitless time, backflush features on at $7.5 \mathrm{~min}$. The PTV temperature program was: starting at $70{ }^{\circ} \mathrm{C}$, stayed for $0.02 \mathrm{~min}$ then increased to $280{ }^{\circ} \mathrm{C}$ at $8.5^{\circ} \mathrm{C} / \mathrm{s}$, maintained for $7.5 \mathrm{~min}$ then 

increased to $330{ }^{\circ} \mathrm{C}$ at $10{ }^{\circ} \mathrm{C} / \mathrm{s}$, held constant until the end of the analysis. The analytes were separated using the following oven program: starting at $60{ }^{\circ} \mathrm{C}$ for $1 \mathrm{~min}$; increased to $120{ }^{\circ} \mathrm{C}$ at $30{ }^{\circ} \mathrm{C} / \mathrm{min}$; increased to $250{ }^{\circ} \mathrm{C}$ at $8{ }^{\circ} \mathrm{C} / \mathrm{min}$; then increased $30^{\circ} \mathrm{C} / \mathrm{min}$ to $260{ }^{\circ} \mathrm{C}$, held for 3 min. The transfer line was kept constant at $300{ }^{\circ} \mathrm{C}$. The ion source was operated at $280{ }^{\circ} \mathrm{C}$ and $11070 \mathrm{eV}$.

\section{2.4. QA/QC}

The method was previously validated with excellent precision and accuracy (Nguyen

113 \& Fromberg, 2020). Several on-going QA/QC procedures were implemented to ensure the

114 quality of obtained data. For each batch of sample, a completely new procedural calibration

115 curve was analyzed together with the samples. All calibration curves showed $\mathrm{r}^{2}$ greater than 116 0.999. Procedural blanks ( $5 \mu \mathrm{L}$ of an extra virgin olive oil) showed no contamination during 117 sample preparations. Reference material (FAPAS ${ }^{\circledR}$ 2656, powder infant formula) was also 118 analyzed in every batch to serve as an on-going QC sample. Since this material does not contain 119 an assigned value for GEs, we used the in-house value for GEs in this material instead. This 120 in-house GEs value was calculated by averaging the results from the analysis of 7 sub-samples 121 of the FAPAS ${ }^{\circledR} 2656$ material (Table S.1). On-going analysis of the reference material 122 demonstrated a very consistent method performance (Table S.1). The concentrations of 123 MCPDEs and GEs in this study were expressed as $\mu \mathrm{g} / \mathrm{kg}$ of bound forms (meaning they were converted to free (2-)3-MCPD or glycidol concentrations, respectively) without any

125 reconstitution correction for powder formula.

\section{3. Results and discussion}

\section{3.1. Occurrence}

128 The concentrations of 2-MCPDEs, 3-MCPDEs, and GEs in standard and specialized infant 129 formula available on the Danish market are described in Table 1. In standard liquid formula, 130 2-MCPDEs, 3-MCPDEs, and GEs were measured at mean concentrations of 2.1, 5.4, and 1.7 
$131 \mu \mathrm{g} / \mathrm{kg}$, respectively. These results are very similar to what we have found in liquid formula 132 collected in 2019 (Nguyen \& Fromberg, 2020). The highest concentrations of MCPDEs 133 isomers were found in liquid products from the manufacturer $\mathrm{C}$ at around $3.3 \mu \mathrm{g} / \mathrm{kg}$ for 2134 MCPDEs and $7.8 \mu \mathrm{g} / \mathrm{kg}$ for 3-MCPDEs. For GEs, however, the product from the manufacturer 135 D contained the highest amount at $4.3 \mu \mathrm{g} / \mathrm{kg}$. Meanwhile, the liquid formula from 136 manufacturers A and B were roughly similar in terms of MCPDEs and GEs contamination.

137 For normal powder formula variety, the average concentrations of 2-MCPDEs, 3-MCPDEs, 138 and GEs were recorded at $11.8,31.0$, and $11.5 \mu \mathrm{g} / \mathrm{kg}$ which were also in good agreement with 139 our preliminary study in 2019 (Nguyen \& Fromberg, 2020). Among all standard powder 140 formula, the highest concentrations of both 2- and 3-MCPDEs were found in a product from 141 the manufacturer $\mathrm{C}$ at $22.7 \mu \mathrm{g} / \mathrm{kg}$ of $2-\mathrm{MCPDEs}$ and $59.6 \mu \mathrm{g} / \mathrm{kg}$ of 3-MCPDEs (Item 23, Table 142 1). It might be plausible that these high concentrations of MCPDEs are related to the high fat content of the product. However, assessment of the MCPDEs concentrations after conversion

144 to fat basis (data not showed) and scatter plots between revealed no such obvious trend. Indeed,

145 the lowest concentrations of MCPDEs were found in two products from the manufacturer A 146 with at least four times lower than other normal powder formula (Item 13 and 14, Table 1). 147 Since items number 13,14 , and 23 were all marketed as organic products with relatively similar 148 fat contents, such a big discrepancy in MCPDEs concentrations might be accounted for by the 149 fact that no palm oil was used in items 13 and 14. It is well-known that palm oil is among the 150 plant oils most affected by MCPDEs contamination due to its high contents of total chlorine 151 and diacylglycerides (Franke, Strijowski, Fleck, \& Pudel, 2009; Oey, van der Fels-Klerx, 152 Fogliano, \& van Leeuwen, 2019). In terms of GEs contamination, normal powder products 153 from manufacturer A generally contained slightly less amount of GEs with the lowest level 154 found in item 13 at $3.0 \mu \mathrm{g} / \mathrm{kg}$. However, the highest amounts were found in products from both 155 manufacturers $\mathrm{A}$ and $\mathrm{B}$ and around $21.5 \mu \mathrm{g} / \mathrm{kg}$. 
156 In specialized powder formula, the GEs concentrations were quite similar to those in normal 157 powder formula with a mean concentration of $11.2 \mu \mathrm{g} / \mathrm{kg}$ (ranged between $1.0-30.7 \mu \mathrm{g} / \mathrm{kg}$ ).

158 Slightly higher MCPDEs concentration in specialized products than standard ones were 159 observed at $18.0 \mu \mathrm{g} / \mathrm{kg}$ for 2-MCPDEs and $49.8 \mu \mathrm{g} / \mathrm{kg}$ for 3-MCPDEs. In order to evaluate if 160 the higher 2-MCPDEs and 3-MCPDEs levels in the specialized formula were significant, some 161 statistical test was carried out at 95\% level fo confidence. Shapiro-Wilk test confirmed the normal distribution of both 2-MCPDEs and 3-MCPDEs in either standard or specialized powder formula. F-test also assured equal variances of the contaminant concentrations in two product types. With the satisfying conditions of normal distribution and equal variances, a ttest for mean comparison was applied. The results from the t-test revealed that both MCPDEs isomers in specialized powder formula showed significantly higher concentrations than those in standard ones $(p<0.05,95 \%$ confidence level). This is the first time such a significant discrepancy was observed for MCPDEs in these two types of infant formula. Leigh \& MacMahon, 2017 also assessed 3-MCPDEs and GEs in different U.S infant formula varieties but found no such trend. In terms of manufacturer differences for specialized formula, the lowest concentrations of 2-MCPDEs $(8.7 \mu \mathrm{g} / \mathrm{kg}), 3$-MCPDEs $(18.3 \mu \mathrm{g} / \mathrm{kg})$, and GEs $(1.0$ $\mu \mathrm{g} / \mathrm{kg}$ ) were found in products from manufacturer A. On the other hand, one product from manufacturer F showed the highest concentrations of both MCPDEs and GEs at $32.9 \mu \mathrm{g} / \mathrm{kg}$ for 2-MCPDEs, $102.8 \mu \mathrm{g} / \mathrm{kg}$ for 3-MCPDEs, and $30.7 \mu \mathrm{g} / \mathrm{kg}$ for GEs.

175 Overall, the occurrence data for MCPDEs and GEs showed that products from manufacturer A

176 tend to contain less amount of these processing contaminants, and specialized powder infant 177 formula is significantly higher in MCPDEs than standard formula products. Despite the 178 elevated concentrations of MCPDEs in specialized products, the levels of both MCPDEs and

179 GEs in infant formula in this study are still among the lowest reported worldwide (Arisseto et 180 al., 2017; Becalski et al., 2015; Beekman et al., 2020; Wöhrlin et al., 2015). For instance, a 
recent study in Brazil showed up to $600 \mu \mathrm{g} / \mathrm{kg}$ of 3-MCPDEs and $750 \mu \mathrm{g} / \mathrm{kg}$ of GEs in infant

182 formula available in this country (Arisseto et al., 2017).

\subsection{Comparison between different powder formula varieties}

184 Due to the lack of specialized liquid formula samples, in this section, only a comparison

185 between standard and specialized powder formula was made. For standard powder formula, 186 there were three varieties namely normal, premium, and organic. Within a brand, normal 187 products are the most basic ones, premium products are branded as such and often packed with 188 more ingredients for various purposes (e.g. digestive improvement, cognitive development 189 enhancement, etc.), and organic products are produced with organic ingredients. Specialized 190 formulas were also divided into three varieties according to their medical purposes: premature

191 for premature-newborn, sensitive for babies with sensitivity toward lactose, and hypoallergenic for infants with allergies toward cow milk.

Previously, Leigh \& MacMahon, 2017 studied different infant formula varieties in the United

States and found hypoallergenic ones contained much lower levels of 3-MCPDE and GEs than other varieties. This was, however, not the case in this study. In fact, hypoallergic infant formula showed a similar amount of GEs and higher MCPDEs concentrations than other varieties (Table 2). In specific, the average concentrations of 2- and 3-MCPDEs in the hypoallergenic formula were 18.6 and $51.9 \mu \mathrm{g} / \mathrm{kg}$, respectively. These values were slightly higher than those found in other specialized products intended for premature babies and infants with sensitive stomach, and significantly higher than all varieties in standard infant formula (ttest at $95 \%$ confidence level, $p<0.05$ ). Interestingly, organic products showed the lowest levels of 2- and 3-MCPDEs at 7.5 and $22.6 \mu \mathrm{g} / \mathrm{kg}$, respectively. From the perspective of GEs contamination, premature formula showed the lowest level at $6.4 \mu \mathrm{g} / \mathrm{kg}$ which were quite similar to premium and organic products, while normal and sensitive products contained the highest GEs concentration. 
206 Overall, the MCPDEs contamination patterns among different varieties were observed as

207 follows: hypoallergenic $\approx$ sensitive $>$ premature $>$ normal $\approx$ premium $>$ organic. For GEs, the

208 trend was: normal $\approx$ sensitive $>$ hypoallergenic $>$ premium $\approx$ organic $>$ premature.

\section{3.3. Exposure estimation and risk assessment}

210 The exposure of exclusively formula-fed infants to different types of formula was estimated

211 according to our previous publication (Nguyen \& Fromberg, 2020). Briefly, the exposure

212 estimation was carried out for two groups of infants according to their age. The first group is

213 newborn children up to 1 month old with $4.2 \mathrm{~kg}$ average body weight, and the second group is

214 infants from 2 to 5 months old with an average body weight of $7.3 \mathrm{~kg}$ (Danish Health Authority,

215 2019). The suggested infant formula consumption per day is $170 \mathrm{~mL} / \mathrm{kg}$ body weight (bw) for

216 the first group, and $110 \mathrm{~mL} / \mathrm{kg}$ bw for the second one (Danish Health Authority, 2019). In order

217 to convert powder formula to ready-to-consume liquid formula, a factor of 7.7 was used (EFSA

218 CONTAM Panel, 2016). Unless stated otherwise, the exposure estimations were carried out

219 using the average concentrations of the chemicals in different type-variety combinations. The

220 estimations of MCPDEs and GEs exposure of Danish infants receiving formula only are

221 described in Table 3.

222 In the first group of newborn and up to 1-month-old babies, the daily exposure to 2-MCPDEs ranged from 0.2 to $0.41 \mu \mathrm{g} / \mathrm{kg}$ bw/day. These ranges for 3-MCPDEs and GEs were $0.52-1.14$ $\mu \mathrm{g} / \mathrm{kg}$ bw/day and $0.09-0.17 \mu \mathrm{g} / \mathrm{kg}$ bw/day, respectively. In the second group of $2-5$ months old babies, the respective daily exposure to 2-MCPDEs, 3-MCPDEs, and GEs were: $0.11-$ $0.24,0.3-0.66$, and $0.09-0.17 \mu \mathrm{g} / \mathrm{kg}$ bw/day. These estimated exposures were in good agreement with what we reported in our preliminary study on infant formula (Nguyen \& Fromberg, 2020). Among all different types of formula, the highest estimated exposure to MCPDEs was via consumption of hypoallergenic products, which were approximately two

230 times higher than the lowest exposure in organic products. For instance, newborn to 1-month 
babies were estimated to expose to 3-MCPDEs at $1.14 \mu \mathrm{g} / \mathrm{kg}$ bw/day if they consumed solely hypoallergenic formula. This value dropped to $0.52 \mu \mathrm{g} / \mathrm{kg}$ bw/day if the organic formula was chosen. Regardless of the variety formula of choice, their estimated daily exposures were still below the Tolerable Daily Intake for 3-MCPDEs (TDI) at $2 \mu \mathrm{g} / \mathrm{kg}$ bw/day set by EFSA (EFSA CONTAM Panel, 2018). However, it is important to note that on an individual product level, one hypoallergenic powder formula (item number 35, Table 1) showed an 3-MCPDEs exposure value of $2.27 \mu \mathrm{g} / \mathrm{kg}$ bw/day for newborn to 1-month infants. This was higher than the TDI established by EFSA and further monitoring is needed to warrant a safe 3-MCPDEs intake level from this product.

240 In terms of GEs exposure, the lowest estimated exposures were found in premature products at $2410.14 \mu \mathrm{g} / \mathrm{kg}$ bw/day for $0-1$ month group, and $0.08 \mu \mathrm{g} / \mathrm{kg}$ bw/day for $2-5$ months group. The highest exposures to GEs were observed in normal products, specifically at $0.31 \mu \mathrm{g} / \mathrm{kg} \mathrm{bw} / \mathrm{day}$ for $0-1$ month group, and $0.18 \mu \mathrm{g} / \mathrm{kg}$ bw/day for $2-5$ months group. Since there is no TDI available for GEs, a margin of exposure (MoE) calculation approach was employed to assess the exposure of infants to GEs. The T25 value of $10.2 \mathrm{mg} / \mathrm{kg}$ bw per day for peritoneal mesothelioma in male rats was used as the no-observed-adverse-effect level for MoE calculation according to EFSA (EFSA CONTAM Panel, 2016). A MoE of 25,000 or higher is considered to of low health concern for GEs exposure. In this study, the estimated MoEs to GEs for $0-1$ month babies ranged between 14000 to 460000 for different individual infant 250 formula products. Specifically, one standard liquid formula product (item number 10, Table 1), two standard powder formula (items number 12 and 19, Table 1), and one specialized powder formula (item number 35, Table 1) showed MoEs smaller than 25000 which indicated a health concern. For the $2-5$ months group, the MoEs were between 22000 to 710000 and two powder formula products (items number 19 and 35, Table 1) showed MoEs smaller than 25000 in this age group. With the assumption that parents are highly loyal to a certain infant formula brand 
or product, the GEs health concern in relation to items number 10,12, 19, and 35 might require

257 further investigations. This is even more true for item number 35 since this item also posses a higher than TDI for estimated 3-MCPDEs exposure in $0-1$ month group. Overall, most standard or specialized infant formula showed no particular health concern for both GEs and

260 3-MCPDEs exposure with a few exceptions as discussed above.

\section{Conclusion}

262 This study investigated a more in-depth occurrence of MCPDEs and GEs in different infant

263 formula types and varieties available in Denmark, including both standard formula and 264 specialized formula for medical purposes. Our finding indicated overall higher levels of 265 MCPDEs but similar levels of GEs in specialized infant formula products in comparison with 266 the standard ones. Among all different varieties, the concentrations of MCPDEs were the 267 highest in the hypoallergenic formula and lowest in the organic formula. Meanwhile, the 268 highest levels of GEs were observed in the normal formula and lowest in the premature 269 formula. Despite the higher levels of MCPDEs in specialized products, on average our 270 estimation of MCPDEs and GEs exposure via formula consumption for Danish infants showed 271 no particular risks. However when individual products were assessed, a hypoallergenic powder 272 formula showed health concerns for both 3-MCPDEs and GEs exposure, while three other 273 standard formulas showed GEs exposure risk. Further investigations in the future might be 274 needed to warrant safety for infants exclusively fed with these products.

\section{Declarations of interest: none}

276 Acknowledgment

277 The authors would like to thank Line Christoffersen for technical assistance during sample 278 preparation. 


\section{References}

280 Arisseto, A. P., Silva, W. C., Scaranelo, G. R., \& Vicente, E. (2017). 3-MCPD and glycidyl

281 esters in infant formulas from the Brazilian market: Occurrence and risk assessment. Food Control, 77, 76-81. https://doi.org/10.1016/j.foodcont.2017.01.028

Becalski, A., Zhao, T., Feng, S., \& Lau, B. P. Y. (2015). A pilot survey of 2- and 3monochloropropanediol and glycidol fatty acid esters in baby formula on the Canadian market 2012-2013. Journal of Food Composition and Analysis, 44, 111-114. https://doi.org/10.1016/j.jfca.2015.08.004

Beekman, J. K., Grassi, K., \& MacMahon, S. (2020). Updated occurrence of 3monochloropropane-1,2-diol esters (3-MCPD) and glycidyl esters in infant formulas purchased in the United States between 2017 and 2019. Food Additives and Contaminants - Part A Chemistry, Analysis, Control, Exposure and Risk Assessment,

BLE (The German Federal Office for Agriculture and Food for the Federal Ministry of Food and Agriculture). (2016). Investigation into the presence of 3-MCPD esters and related compounds in foods. Retrieved from

Cao, R., Wang, S., Li, C., Liu, W., Zhou, H., \& Yao, Y. (2019). Molecular Reaction Mechanism for the Formation of 3-chloropropanediol Esters in Oils and Fats. Journal of Agricultural and Food Chemistry. https://doi.org/10.1021/acs.jafc.8b06632

Cheng, W., Liu, G., \& Liu, X. (2016). Formation of Glycidyl Fatty Acid Esters Both in Real Edible Oils during Laboratory-Scale Refining and in Chemical Model during High Temperature Exposure. Journal of Agricultural and Food Chemistry, 64(29), 5919- 
304 Danish Health Authority. (2019). Ernæring til spædbørn og småbørn. Retrieved August 8, 2019, from https://www.sst.dk/da/sundhed-oglivsstil/ernaering/ /media/2986643F11A44FA18595511799032F85.ashx

Dipasquale, V., Serra, G., Corsello, G., \& Romano, C. (2020). Standard and Specialized Infant Formulas in Europe: Making, Marketing, and Health Outcomes. Nutrition in

EFSA CONTAM Panel. (2016). Risks for human health related to the presence of 3- and 2monochloropropanediol (MCPD), and their fatty acid esters, and glycidyl fatty acid esters in food. EFSA Journal, 14(5). https://doi.org/10.2903/j.efsa.2016.4426

EFSA CONTAM Panel. (2018). Update of the risk assessment on 3-monochloropropane diol and its fatty acid esters. EFSA Journal, 16(1), 1-48. https://doi.org/10.2903/j.efsa.2018.5083

Franke, K., Strijowski, U., Fleck, G., \& Pudel, F. (2009). Influence of chemical refining process and oil type on bound 3-chloro-1,2-propanediol contents in palm oil and rapeseed oil. LWT - Food Science and Technology, 42(10), 1751-1754.

IARC. (2000). Glycidol. IARC Monographs, 1-18. Retrieved from https://monographs.iarc.fr/ENG/Monographs/vol77/mono77-19.pdf

IARC. (2013). 3-Monochloro-1,2-propanediol. IARC Monographs, 101.

Kuhlmann, J. (2011). Determination of bound 2,3-epoxy-1-propanol (glycidol) and bound monochloropropanediol (MCPD) in refined oils. European Journal of Lipid Science and Technology, 113(3), 335-344. https://doi.org/10.1002/ejlt.201000313 
Leigh, J., \& MacMahon, S. (2017). Occurrence of 3-monochloropropanediol esters and glycidyl esters in commercial infant formulas in the United States. Food Additives and Contaminants - Part A Chemistry, Analysis, Control, Exposure and Risk Assessment, 34(3), 356-370. https://doi.org/10.1080/19440049.2016.1276304

Nguyen, K. H., \& Fromberg, A. (2020). Monochloropropanediol and glycidyl esters in infant formula and baby food products on the Danish market: Occurrence and preliminary risk assessment. Food Control, 110(November 2019), 106980. https://doi.org/10.1016/j.foodcont.2019.106980

Oey, S. B., van der Fels-Klerx, H. J., Fogliano, V., \& van Leeuwen, S. P. J. (2019). Mitigation Strategies for the Reduction of 2- and 3-MCPD Esters and Glycidyl Esters in the Vegetable Oil Processing Industry. Comprehensive Reviews in Food Science and Food Safety, 18(2), 349-361. https://doi.org/10.1111/1541-4337.12415

Wöhrlin, F., Fry, H., Lahrssen-Wiederholt, M., \& Preiß-Weigert, A. (2015). Occurrence of fatty acid esters of 3-MCPD, 2-MCPD and glycidol in infant formula. Food Additives and Contaminants - Part A Chemistry, Analysis, Control, Exposure and Risk Assessment, 32(11), 1810-1822. https://doi.org/10.1080/19440049.2015.1071497

Zhang, Z., Gao, B., Zhang, X., Jiang, Y., Xu, X., \& Yu, L. (2015). Formation of 3monochloro-1,2-propanediol (3-MCPD) Di- and monoesters from tristearoylglycerol (TSG) and the potential catalytic effect of $\mathrm{Fe} 2+$ and Fe3+. Journal of Agricultural and Food Chemistry, 63(6), 1839-1848. https://doi.org/10.1021/jf5061216 
Table 1. Concentrations of 2-MCPDEs, 3-MCPDEs, and GEs in standard and specialized infant formula available on the Danish market

\begin{tabular}{|c|c|c|c|c|c|c|}
\hline Item & Brand & $\begin{array}{l}\text { Specific } \\
\text { variety }\end{array}$ & $\begin{array}{l}\text { Fat content } \\
(\%)^{*}\end{array}$ & $\begin{array}{l}\text { 2-MCPDEs } \\
(\mu \mathrm{g} / \mathrm{kg})^{* *}\end{array}$ & $\begin{array}{l}\text { 3-MCPDEs } \\
(\mu \mathrm{g} / \mathrm{kg})^{* *}\end{array}$ & $\begin{array}{l}\text { GEs } \\
(\mu \mathrm{g} / \mathrm{kg})^{* *}\end{array}$ \\
\hline \multicolumn{7}{|c|}{ Liquid formula, standard } \\
\hline 1 & $\mathrm{~A}$ & Normal & 3.6 & 1.9 & 6.2 & 1.9 \\
\hline 2 & A & Organic & 3.6 & 1.6 & 3.1 & 1.0 \\
\hline 3 & A & Normal & 3.2 & 1.7 & 5.3 & 1.6 \\
\hline 4 & $\mathrm{~A}$ & Organic & 3.2 & 1.2 & 3.3 & 0.7 \\
\hline 5 & A & Normal & 3 & 1.2 & 3.9 & 0.5 \\
\hline 6 & $\mathrm{~B}$ & Normal & 3.5 & 1.9 & 5.1 & 1.0 \\
\hline 7 & $\mathrm{~B}$ & Normal & 2.9 & 2.1 & 5.9 & 1.0 \\
\hline 8 & $\mathrm{C}$ & Normal & 3.6 & 3.2 & 7.7 & 2.2 \\
\hline 9 & $\mathrm{C}$ & Normal & 3.1 & 3.3 & 7.9 & 2.3 \\
\hline 10 & $\mathrm{D}$ & Normal & 3.6 & 2.5 & 5.9 & 4.3 \\
\hline Mean & & & & 2.1 & 5.4 & 1.7 \\
\hline \multicolumn{7}{|c|}{ Powder formula, standard } \\
\hline 11 & A & Premium & 26 & 14.5 & 36.7 & 9.4 \\
\hline 12 & $\mathrm{~A}$ & Normal & 28 & 15.9 & 43.7 & 21.5 \\
\hline 13 & A & Organic & 28 & 1.9 & 5.3 & 8.1 \\
\hline 14 & $\mathrm{~A}$ & Organic & 24 & 1.1 & 8.1 & 3.0 \\
\hline 15 & $\mathrm{~A}$ & Premium & 23 & 11.1 & 30.7 & 7.3 \\
\hline 16 & $\mathrm{~A}$ & Normal & 28 & 7.6 & 22.4 & 3.8 \\
\hline 17 & A & Normal & 22 & 20.1 & 42.3 & 8.5 \\
\hline 18 & $\mathrm{~B}$ & Normal & 27 & 13.3 & 32.5 & 15.4 \\
\hline 19 & $\mathrm{~B}$ & Normal & 27 & 22.3 & 50.1 & 21.8 \\
\hline 20 & $\mathrm{~B}$ & Normal & 19 & 13.2 & 35.6 & 14.5 \\
\hline 21 & $\mathrm{~B}$ & Normal & 19 & 8.0 & 26.0 & 13.7 \\
\hline 22 & $\mathrm{~B}$ & Normal & 20 & 9.7 & 23.6 & 13.6 \\
\hline 23 & $\mathrm{C}$ & Organic & 28 & 22.7 & 59.6 & 13.4 \\
\hline 24 & $\mathrm{C}$ & Organic & 22.5 & 4.3 & 17.2 & 7.6 \\
\hline Mean & & & & 11.8 & 31 & 11.5 \\
\hline \multicolumn{7}{|c|}{ Powder formula, specialized } \\
\hline 25 & $\mathrm{~A}$ & Premature & 26.4 & 22.1 & 63.7 & 11.7 \\
\hline 26 & $\mathrm{~A}$ & Premature & 18 & 8.9 & 18.3 & 1.0 \\
\hline 27 & $\mathrm{~A}$ & Sensitive & 28 & 26.5 & 69.2 & 13.5 \\
\hline 28 & $\mathrm{~A}$ & Sensitive & 25 & 18.5 & 47.5 & 15.8 \\
\hline 29 & $\mathrm{~A}$ & Hypoallergenic & 26 & 19.6 & 45.3 & 13.6 \\
\hline 30 & A & Hypoallergenic & 23 & 8.7 & 32.2 & 8.2 \\
\hline 31 & $\mathrm{~A}$ & Hypoallergenic & 26 & 20.6 & 65.9 & 14.8 \\
\hline 32 & A & Hypoallergenic & 24.6 & 17.2 & 47.9 & 8.8 \\
\hline 33 & B & Sensitive & 27 & 13.5 & 36.0 & 11.1 \\
\hline 34 & B & Sensitive & 19 & 11.4 & 39.1 & 13.0 \\
\hline 35 & $\mathrm{~F}$ & Hypoallergenic & 26 & 32.9 & 102.8 & 30.7 \\
\hline 36 & $\mathrm{~F}$ & Hypoallergenic & 25 & 20.3 & 55.6 & 9.9 \\
\hline
\end{tabular}




\begin{tabular}{|lllllll|}
37 & $\mathrm{~F}$ & Hypoallergenic & 20 & 16.9 & 47.1 & 5.4 \\
38 & $\mathrm{~F}$ & Hypoallergenic & 28 & 18.6 & 67.5 & 6.2 \\
39 & $\mathrm{G}$ & Hypoallergenic & 25.7 & 24.3 & 56.8 & 12.0 \\
40 & $\mathrm{G}$ & Hypoallergenic & 21.8 & 16.7 & 40.8 & 9.5 \\
41 & $\mathrm{H}$ & Hypoallergenic & 22 & 16.6 & 33.9 & 7.9 \\
42 & $\mathrm{H}$ & Hypoallergenic & 24.5 & 10.2 & 26.4 & 9.2 \\
Mean & & & & 18.0 & 49.8 & 11.2 \\
\hline
\end{tabular}

*: information specified on the labels

**: $\mu \mathrm{g} / \mathrm{kg}$ product expressed as free form equivalent 
Table 2. Mean concentrations of 2-MCPDEs, 3-MCPDEs, and GEs in Danish powder infant formula categorized by variety

\begin{tabular}{|lllll|}
\hline Type & Variety & $\begin{array}{l}\text { 2-MCPDEs } \\
(\mu \mathrm{g} / \mathrm{kg})^{*}\end{array}$ & $\begin{array}{l}3-\mathrm{MCPDEs} \\
(\mu \mathrm{g} / \mathrm{kg})^{*}\end{array}$ & $\begin{array}{l}\text { GEs } \\
(\mu \mathrm{g} / \mathrm{kg})^{*}\end{array}$ \\
\hline Standard & Normal $(\mathrm{n}=8)$ & 13.8 & 34.5 & 14.1 \\
& Premium $(\mathrm{n}=2)$ & 12.8 & 33.7 & 8.3 \\
& Organic $(\mathrm{n}=4)$ & 7.5 & 22.6 & 8.0 \\
Specialized & Premature $(\mathrm{n}=2)$ & 15.5 & 41.0 & 6.4 \\
& Sensitive $(\mathrm{n}=4)$ & 17.5 & 47.9 & 13.3 \\
& Hypoallergenic $(\mathrm{n}=12)$ & 18.6 & 51.9 & 11.3 \\
\hline
\end{tabular}

*: $\mu \mathrm{g} / \mathrm{kg}$ product expressed as free form equivalent 
Table 3. Estimated exposure of Danish infants to 2-MCPDEs, 3-MCPDEs, and GEs via formula consumption according to different formula varieties $(\mu \mathrm{g} / \mathrm{kg} \mathrm{bw} / \mathrm{day})$

\begin{tabular}{|l|c|c|c|c|c|c|}
\hline Compound & \multicolumn{2}{|c|}{ 2-MCPDEs } & \multicolumn{2}{|c|}{ 3-MCPDEs } & \multicolumn{2}{c|}{ GEs } \\
\hline Age group (months) & $0-1$ & $2-6$ & $0-1$ & $2-6$ & $0-1$ & $2-6$ \\
\hline Standard, Normal & 0.34 & 0.20 & 0.89 & 0.51 & 0.31 & 0.18 \\
Standard, Premium & 0.28 & 0.16 & 0.74 & 0.43 & 0.18 & 0.11 \\
Standard, Organic & 0.20 & 0.11 & 0.52 & 0.30 & 0.16 & 0.09 \\
\hline Specialized, Premature & 0.34 & 0.20 & 0.91 & 0.52 & 0.14 & 0.08 \\
Specialized, Sensitive & 0.39 & 0.22 & 1.06 & 0.61 & 0.29 & 0.17 \\
Specialized, Hypoallergenic & 0.41 & 0.24 & 1.14 & 0.66 & 0.25 & 0.14 \\
\hline
\end{tabular}


Table S.1. Concentrations of 2-MCPDEs, 3-MCPDEs, and GEs in FAPAS ${ }^{\circledR} 2656$ infant formula samples analyzed along with real samples in different batches $(\mu \mathrm{g} / \mathrm{kg}$, free form equivalent)

\begin{tabular}{lllllll}
\hline & $\begin{array}{l}\text { FAPAS } \\
\text { assigned } \\
\text { value }\end{array}$ & $\begin{array}{l}\text { In-house } \\
\text { assigned } \\
\text { value }\end{array}$ & Range for $|z|^{* *} \leq 2$ & Batch 1 & Batch 2 & Batch 3 \\
\hline 2-MCPDEs & 16.4 & 16.6 & $9.16-23.6$ & 15.8 & 17.4 & 15.0 \\
3-MCPDEs & 44 & 40 & $24.6-63.4$ & 43.6 & 40.3 & 40.6 \\
GEs & 20.7 & & 18.4 & 22.7 & 16.7 \\
\hline
\end{tabular}

*: Determined from in-house analysis of seven sub-samples of FAPAS ${ }^{\circledR} 2656$ material

${ }^{* *}$ : z-score derived from a proficiency test using FAPAS ${ }^{\circledR} 2656$ reference material 